\title{
INHIBICIÓN DE LOS RECEPTORES DE LA ANGIOTENSINA Y DE LA NEPRILISINA: UNA NUEVA ESPERANZA EN EL TRATAMIENTO DE LA INSUFICIENCIA CARDÍACA
}

\author{
ANGIOTENSIN RECEPTOR BLOCKER AND NEPRILYSIN INHIBITORS: \\ A NEW HOPE IN THE TREATMENT OF HEART FAILURE
}

\section{CAROLINA G. NASO'}

\section{RESUMEN}

La insuficiencia cardíaca (IC) es un trastorno progresivo frente al cual se activan sistemas reguladores, como el sistema renina-angiotensina-aldosterona (SRAA) y mecanismos contrarreguladores, como los péptidos natriuréticos. Es ya reconocido el tratamiento neurohormonal de la IC, que ha demostrado disminuir la mortalidad en dicha patología, como lo son los inhibidores del SRAA, los betabloqueantes y los antagonistas de los mineralocorticoides. Actualmente, toma importancia un nuevo grupo de fármacos que recientemente también demostró disminuir mortalidad, los inhibidores de la recaptación de neprilisina y de la angiotensina. Los péptidos natriuréticos son hormonas secretadas por el corazón que poseen propiedades pleiotrópicas protectoras del sistema cardiovascular, secretadas frente al estiramiento parietal cardíaco, y que son degradados por la neprilisina. Sobre esta base fisiopatológica, se originó un nuevo fármaco compuesto por el sacubitril (inhibidor de la degradación de la neprilisina), con el valsartán (inhibidor de los receptores de angiotensina II) que demostró disminuir la mortalidad en IC contra el enalapril. El objetivo de esta monografía es realizar una revisión exhaustiva de la fisiopatología de la IC, del SRAA y de los péptidos natriuréticos, para posteriormente presentar al fármaco sacubitril/valsartán su mecanismo de acción y evidencia actual.

Palabras clave: insuficiencia cardíaca; péptidos natriuréticos; neprilisina; valsartán.

\section{ABSTRACT}

Heart failure (HF) is a progressive disorder against which regulatory systems are activated, such as the Renin-Angiotensin-Aldosterone system (RAAS) and counterregulatory mechanisms, such as natriuretic peptides. The neurohormonal treatment of $\mathrm{HF}$ is already well-known, which has been shown to reduce mortality in this pathology, as are the RAAS inhibitors, beta-blockers and mineralocorticoid antagonists. Currently, a new group of drugs that recently also showed a decrease in mortality, the inhibitors of the reuptake of neprilysin and angiotensin, is becoming important. $\mathrm{Na}$ triuretic peptides are hormones secreted by the heart that have protective pleiotropic properties of the cardiovascular system, secreted against cardiac parietal stretch, and that are degraded by neprilysin. On this pathophysiological basis, a new drug composed of sacubitril (inhibitor of neprilysin degradation) was originated, with valsartan (inhibitor of angiotensin II receptors) that showed to decrease the mortality in $\mathrm{HF}$ against enalapril. The objective of this monograph is to carry out an exhaustive review of the pathophysiology of HF, RAAS and natriuretic peptides, to subsequently present the drug sacubitril / valsartan, its mechanism of action and current evidence.

Keywords: heart failure, natriuretic peptides, valsartan, neprilysin.

REVISTA CONAREC 2018;33(145):165-175 | DOI:10.32407/RCON/2018145/0165-0175

\section{INTRODUCCIÓN}

La insuficiencia cardíaca (IC) es un trastorno progresivo que se inicia después de un acontecimiento índice capaz de reducir el inotropismo cardíaco. En la mayoría de los casos los pacientes inicialmente se mantienen asintomáticos u oligosintomáticos gracias a la puesta en juego de mecanismos compensadores como el sistema neurohormonal (sistema nervioso autónomo, sistema renina-angiotensina-aldosterona -SRAA-, vasopresina), sosteniendo en límites fisiológicos las funciones del corazón, de manera de preservar la homeostasis cardiovascular del paciente en las primeras etapas de esta patología'.

En etapas avanzadas, la activación sostenida de los sistemas neurohormonales lleva al remodelado del ventrículo izquierdo, generando el cuadro clínico florido de IC. A partir de esta pérdida de compensación, la progresión de la enfermedad sigue un curso independiente y defini-

1. Residente de Cardiología, Hospital Ramos Mejía.

$\triangle$ Correspondencia:Dra. Carolina Giselle Naso. Avenida Chivilcoy 4406 CP 1419 CABA, Rep. Argentina.Email:docnasocarolina@gmail.com

Los autores declaran no poseer conflictos de intereses.

Recibido: 15/10/2017 | Aceptado: 03/03/2018 tivo, acelerando su progresión natural y disminuyendo la supervivencia del paciente. Frente a esta situación existen mecanismos contrarreguladores que se contraponen a estos efectos perjudiciales, como los péptidos natriuréticos que son hormonas producidas por el corazón que poseen propiedades pleiotrópicas protectoras del sistema cardiovascular. Estos péptidos son degradados por una enzima, la neprilisina.

En base a este sustrato fisiopatológico es que surgió el sacubitril, un nuevo fármaco que se basa en el bloqueo de la neprilisina que, combinado con el de los receptores de la angiotensina II (valsartán), tiene como objetivo el aumento de los péptidos natriuréticos más el bloqueo del SRAA para ejercer su efecto favorable en IC con fracción de eyección deteriorada. Este nuevo fármaco demostró disminuir la mortalidad en un ensayo clínico randomizado cuando fue comparado con enalapril ${ }^{2,3}$

Teniendo en cuenta esta información, el tema de esta monografía fue elegido en base a la gran incidencia de esta patología y al daño que ella produce a nivel individual, poblacional y sanitario, y por el interés preventivo mediante su tratamiento específico, previo al arribo a un curso irreversible. A su vez, plantear un posible cambio de paradigma en el tratamiento de la insuficiencia cardíaca, siendo que por primera vez un fármaco nuevo demuestra superioridad frente al enalapril, la piedra angular de su tratamiento desde hace 30 años. Por lo tanto, el objetivo principal de esta monografía es realizar una revisión exhaustiva de la fisiopatología de la IC, del SRAA y de los péptidos natriuréticos, para posteriormente presentar al nuevo fármaco, sacubitril/valsartán, su mecanismo de acción y evidencia actual. 


\section{DESARROLLO}

\section{CONCEPTOS BÁSICOS DE INSUFICIENCIA CARDÍACA}

La IC es un síndrome caracterizado por la presencia de signos y síntomas típicos causados por anomalías cardíacas estructurales o funcionales, que producen reducción del gasto cardíaco y elevación de las presiones intracardíacas ${ }^{1,2}$

Es una entidad de importancia, con prevalencia e incidencia aumentada en nuestros tiempos, debido en gran parte al auge de las enfermedades crónicas que le dan origen (enfermedad coronaria, diabetes e hipertensión arterial, principalmente), el aumento de la expectativa de vida y la mayor supervivencia de los pacientes. Esto genera al sistema de salud un aumento en el número de hospitalizaciones, en la mortalidad y en los costos asociados a su tratamiento, sumado al gran deterioro de la calidad de vida del paciente ${ }^{3}$.

En cuanto al tratamiento neurohormonal de la IC, contamos con tres grupos de fármacos que han demostrado disminuir la mortalidad: los inhibidores del SRAA ${ }^{4-7}$, los betabloqueantes ${ }^{8-12}$ y los antagonistas de los mineralocorticoides ${ }^{13-15}$. Respecto a los bloqueantes de los receptores de la angiotensina, no demostraron disminución significativa de la mortalidad ${ }^{16,17}$ ni que sean mejores respecto de los inhibidores de la enzima convertidora de angiotensina (IECA $)^{18,19}$; por lo tanto, su indicación se reserva para aquellos pacientes que no toleren los IECA.

\section{FISIOPATOLOGÍA}

El desarrollo de la insuficiencia cardíaca comienza con un daño miocárdico primario que produce disfunción ventricular, lo cual lleva a una disminución de la descarga sistólica con la consecuente caída en el volumen minuto y disminución en la oferta tisular de oxígeno. Para contrarrestar estas manifestaciones y preservar la homeostasis cardiocirculatoria en las primeras etapas de esta enfermedad, se ponen en marcha dos mecanismos adaptativos: la activación neurohormonal (con el sistema renina-angiotensina-aldosterona -SRAA- y el sistema nervioso simpático -SNS-) y el remodelado ventricular ${ }^{20}$. Por disminución de la presión arterial, se activa el SRAA, el cual retiene agua y sodio, aumentando de esta forma la precarga del ventrículo izquierdo (VI), lo cual, por la ley de Frank Starling, genera inicialmente un aumento de la fuerza de contracción incrementando la descarga sistólica y de esta manera el volumen minuto. Por estimulación del SNS, se produce mayor descarga adrenérgica, que por estímulo beta aumenta la frecuencia cardíaca y la contractilidad del ventrículo izquierdo, y por estímulo alfa genera vasoconstricción.

Estos mecanismos compensan transitoriamente la caída en el volumen minuto, pero sostenidos en el tiempo, terminan siendo deletéreos para el músculo cardíaco. La sobrecarga crónica de volumen y de presión y el aumento del estrés parietal provocan dilatación e hipertrofia ventricular, aumentando el consumo miocárdico de oxígeno que, junto con la isquemia debida a la disminución de la perfusión miocárdica por el aumento de la frecuencia cardíaca y el acortamiento del tiempo de fin de diástole, generan un "círculo vicioso" que contribuye al remodelado ventricular.
Para contrarrestar estos efectos perjudiciales, nuestro organismo pone en funcionamiento mecanismos contrarreguladores: sistemas vasodilatadores como el óxido nítrico y el sistema de péptidos natriuréticos, que intentan compensar el daño que se auto perpetúa en la IC, con acción vasodilatadora, diurética, natriurética y lucitrópica, y con efecto beneficioso sobre el remodelado ventricular y la fibrosis.

\section{SISTEMA RENINA ANGIOTENSINA ALDOSTERONA}

El sistema renina-angiotensina-aldosterona (SRAA) es uno de los mecanismos compensadores que se activan en la insuficiencia cardía$\mathrm{ca}^{21}$. La renina es una aspartil proteasa secretada por las células yuxtaglomerulares de las paredes de las arteriolas eferentes del riñón, escinde el angiotensinógeno circulante (sintetizado en el hígado) para formar angiotensina I, proteasa desprovista de acción biológica. Su secreción es estimulada por tres vías: (a) vía mácula densa (células de la rama ascendente gruesa cortical renal): al detectar disminución de la concentración de cloruro de sodio que llega a este punto, se estimula la secreción de renina; (b) vía del barorreceptor renal: en cuanto detecta disminución de la presión en la arteriola aferente (por hipotensión arterial sistémica), se estimula la secreción de renina; (c) vía del receptor beta adrenérgico: la liberación de noradrenalina de terminales nerviosas simpáticas produce liberación de renina por la estimulación del receptor $\beta 1$.

En este contexto, la enzima convertidora de angiotensina, secretada principalmente por las células endoteliales de los pulmones, cataliza la conversión de angiotensina I en angiotensina II. Este proceso no se realiza solamente en el riñón, sino también a nivel local en otros tejidos (pared vascular, pulmones, gónadas, sistema nervioso central y el corazón). El SRAA local está activado en los pacientes con disfunción ventricular izquierda asintomática, y ello tiene que ver con la progresión hacia una etapa clínica de la enfermedad. Ello explica por que el tratamiento con inhibidores del SRAA en etapa asintomática, pero con disfunción del ventrículo izquierdo, demostró reducir la tasa de progresión a insuficiencia cardíaca clínica.

Los efectos deletéreos de la activación del SRAA se basan principalmente en la activación de los receptores del tipo 1 de la angiotensina II (AT II). Su estimulación produce varios efectos, entre ellos, una potente respuesta vasoconstrictora arteriovenosa, ya sea por acción directa, activando los receptores para AT II, como por acción indirecta, a través de la activación del tono simpático central y periférico, estimulando la liberación de vasopresina, endotelina y aldosterona. También produce efectos tróficos a largo plazo (como hipertrofia, fibrosis y remodelado cardíaco y vascular), lo que contribuye a reducir la distensibilidad vascular, aumentar la rigidez ventricular y promover estímulos arrítmicos. A su vez, genera disfunción de los barorreceptores, que origina una activación mantenida del sistema nervioso simpático y del SRAA, de manera que aun cuando haya retención hidrosalina interpretarán depleción de volumen y estimularán la respuesta hipertensora. También aumenta la actividad de la nicotinamida adenina dinucleótido 2' fosfato oxidasa, incrementando la producción de radicales libres y el estrés oxidativo, lo cual resulta en mayor inflamación. En el riñón, aumenta la reab- 
sorción de sodio y agua, tanto por una acción directa a nivel del túbulo proximal, como indirectamente, a través de la liberación de aldosterona que, como veremos a continuación, actúa a nivel del túbulo distal y colector.

La aldosterona genera efectos extracardiovasculares y cardiovasculares, similares a los de la AT II. Entre los primeros, a nivel renal reabsorbe sodio a cambio de potasio en los segmentos distales de las nefronas que, análogamente a la AT II, generando el ascenso de la tensión arterial y mayor retención de sodio; todo ello promueve la aparición de edema, hipokalemia e hipomagnesemia, y con ello, las arritmias ventriculares. A nivel del sistema nervioso central, genera aumento de la sed y apetito por la sal. A nivel cardiovascular, la aldosterona produce aumento del tono vascular por distintos mecanismos: aumento de la respuesta a catecolaminas, disminución de la sensibilidad de los barorreceptores carotídeos, y libera de esta manera al tono simpático, lo que generaría también la aparición de arritmias cardíacas. Es por ello que los pacientes con insuficiencia cardíaca presentan una frecuencia cardíaca persistentemente elevada y vasoconstricción sistémica. A su vez, promueve la inflamación sistémica a nivel perivascular e intersticial, generando lisis del colágeno y fibrosis, favoreciendo el remodelado cardíaco y vascular. Estos dos sucesos sumados tienen que ver con la disminución de la capacidad de vasodilatación periférica y con la disfunción diastólica, generada por el aumento del tejido de contenido fibroso a nivel del intersticio miocárdico.

El "escape de aldosterona" es un fenómeno producido en pacientes tratados crónicamente con IECA, en quienes aumenta la producción de aldosterona por varios mecanismos: la reducción de la producción de AT II lleva a un aumento reflejo de la producción de renina, efecto que sobrepasa al efecto inhibidor de la enzima convertidora, generando, por lo tanto, aumento tanto de la AT II como de la aldosterona; el aumento del potasio plasmático atribuible al tratamiento, más la disfunción renal frecuente en los pacientes con IC; y el aumento de los niveles de ACTH, que activan el eje córtico-suprarrenal. Este hecho parece ser la base del tratamiento con antialdosterónicos ${ }^{22}$.

Podemos resumir que, en base a todos estos efectos, se generarán los siguientes efectos hemodinámicos: aumento de la precarga (por expansión de volumen gracias a la retención de sodio), aumento de la poscarga (por producir hipertensión arterial), aumento de la frecuencia cardiaca (por respuesta simpática), y con ello, aumento de las demandas miocárdicas de oxígeno.

En este contexto, en el cual la activación de sistemas compensadores en un principio, que se tornan en perjudiciales a largo plazo, existen otros sistemas neurohormonales contrarreguladores que se activan con el fin de tratar de compensar los efectos perjudiciales. Entre ellos, la prostaglandina E2 (vasodilatadora y potenciadora de la excreción renal de sodio), la prostaciclina, el óxido nítrico y el sistema de los péptidos natriuréticos, de los cuales trataremos a continuación ${ }^{23}$.

\section{PÉPTIDOS NATRIURÉTICOS}

Debemos el descubrimiento de los péptidos natriuréticos al bioquímico argentino Adolfo J. De Bold, quien en 1981 en la
Universidad de Toronto, Canadá, llevó a cabo un protocolo científico que se basó en la comparación de la acción de extractos homogeneizados de miocardio auricular, ventricular, y de ambos, de corazón de ratas, recalcando la presencia de gránulos parecidos morfológica e histológicamente a las hormonas únicamente en los miocardiocitos auriculares. Con ello, generó respectivamente tres extractos que fueron inyectados en otras ratas y observó en el grupo perteneciente al extracto atrial el aumento de la natriuresis y de la kaliuresis, el descenso de la presión arterial, sin caída del filtrado glomerular. Por medio del presente experimento, se describió por primera vez un potente inhibidor de la reabsorción renal de sodio a nivel cardíaco, el factor natriurético atrial, y se sentaron las bases para el estudio de las propiedades endocrinológicas del corazón ${ }^{24}$.

\section{A. TIPOS Y FUNCIONES DE LOS PÉPTIDOS NATRIURÉTICOS}

Los péptidos natriuréticos están comprendidos en un grupo de diferentes hormonas cardíacas con propiedades pleiotrópicas protectoras del sistema cardiovascular ${ }^{25}$ :

Péptido natriurético atrial (ANP). Es un péptido producido únicamente en las aurículas. Es un contrarregulador natural del sistema renina-angiotensina-aldosterona y del sistema nervioso simpático, por sus propiedades antifibróticas, natriuréticas, kaliuréticas, vasodilatadoras y diuréticas. Se almacena en gránulos en los miocardiocitos de las aurículas y se libera como hormona activa estimulada por el aumento de tensión transmural en las mismas, secundario al aumento de volumen. Su tiempo de vida media es de tres minutos.

Péptido natriurético cerebral (BNP). Debe su nombre por su unión observada a receptores en el cerebro ${ }^{26}$, lo cual a la vez demostró su acción contrarreguladora del sistema nervioso simpático. Es un péptido secretado preferencialmente por el ventrículo, que posee las mismas acciones que el ANP, pero que presenta mayor vida media (21 minutos). Su secreción es estimulada por el aumento de la tensión parietal a nivel ventricular ${ }^{27}$. El BNP se secreta como prohormona glicosilada. En circulación, es sucesivamente deglicosilado y clivado por la corina en su forma activa, y en su forma inactiva (más conocida como NT-proBNP) ${ }^{28}$.

Péptido natriurético tipo C (CNP). Es un péptido liberado por células endoteliales y renales como prohormona, clivado en circulación a sus formas activas, que posee propiedades vasodilatadoras y antifibróticas. Su secreción es estimulada por citoquinas y agonistas endoteliales como la acetilcolina.

\section{B. MECANISMO DE ACCIÓN Y DEGRADACIÓN DE LOS PÉPTIDOS NATRIURÉTICOS}

Respecto a su mecanismo de acción, ANP y BNP se ligan a receptores de membrana tipo guanil ciclasa tipo A (GC-A), mientras que CNP se liga a los receptores tipo B (GC-B), distribuidos principalmente en riñón y corazón, y ejercen sus funciones intracelulares mediante segundo mensajero vía GMP cíclico a nivel intracelular (Figura 1).

La neprilisina, también conocida como endopeptidasa neutra, es la principal enzima responsable de la degradación de los péptidos natriuréticos en fragmentos inactivos. Se encuentra ampliamente expresada en nuestro organismo: se encontró en riñón, pulmones, cé- 


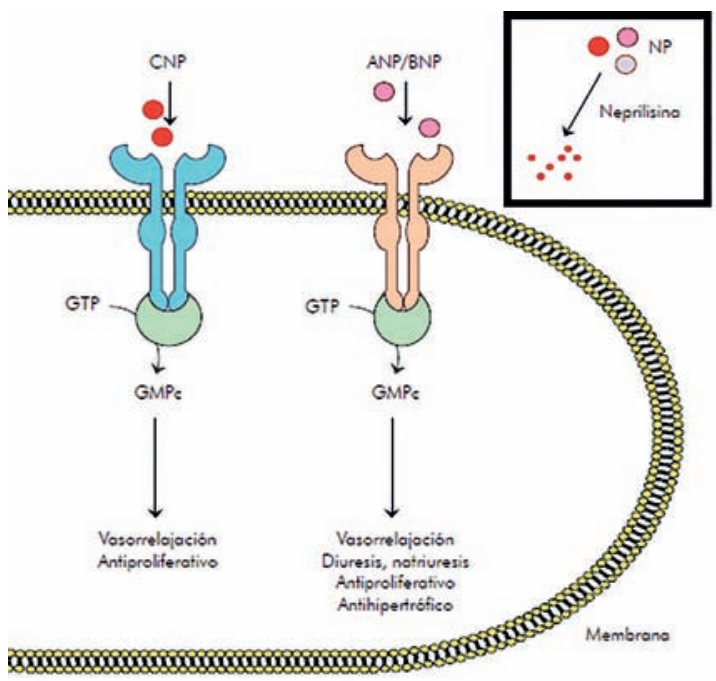

Figura 1. Señalización intracelular de los péptidos natriuréticos. Tanto el ANP (péptido natriurético auricular) como el BNP (péptido natriurético cerebral) se ligan al mismo receptor. La neprilisina es la principal enzima encargada de la degradación de estos. ANP: péptido natriurético auricular. BNP: péptido natriurético cerebral. CNP: péptido natriurético tipo C. NP: péptidos natriuréticos. GTP: guanosín trifosfato. GMPC: guanosín monofosfato cíclico. Modificado de Manzur F, Villarreal T, Moneriz C. Inhibición dual de la neprilisina y el receptor de angiotensina II: nueva estrategia prometedora en el tratamiento de la enfermedad cardiovascular. Rev Colomb Cardiol 2013;20(6):388

lulas endoteliales, células de músculo liso, cardiomiocitos, adipocitos y en cerebro, con mayor concentración en las células de túbulo renal proximal. A su vez, es la responsable de la degradación de otros péptidos, involucrados en funciones cardiovasculares, como angiotensina I y II, bradiquininas y endotelina-1, y no involucrados en ellas, como sustancia P, proteína beta amiloidea y gastrina. La neprilisina no degrada al NT-proBNP, por lo cual se utiliza como biomarcador para diagnóstico y pronóstico en IC ${ }^{29}$.

\section{C. ACCIONES Y UTILIDADES}

Uno de sus principales efectos es la vasodilatación, de hecho se ha reportado la disminución de la presión de aurícula derecha, de la arteria pulmonar, de la presión de enclavamiento pulmonar y de las resistencias vasculares en falla cardíaca congestiva tras la infusión de BNP. Los péptidos natriuréticos promueven la excreción de sodio y agua mediante la inhibición de la reabsorción de sodio en la porción proximal y distal de la nefrona, sin alterar el filtrado glomerular mediante la regulación del feedback túbulo-glomerular, lo cual mejora la función hemodinámica y renal en pacientes con falla cardíaca. Los efectos diuréticos, natriuréticos y hemodinámicos, a su vez, resultan de una inhibición de los sistemas renina-angiotensina-aldosterona y del sistema nervioso simpático. También se han hallado otras funciones mediadas por estos péptidos, como la estimulación de la lipólisis activada por el ANP en los receptores NPR-A de los adipocitos, generando ácidos grasos libres que se cree que contribuirían como sustrato para el trabajo cardíaco ${ }^{30}$. Otras de las funciones de los péptidos natriuréticos es la antifibrótica, demostrada por la inhibición de la hipertrofia cardíaca que generan la angiotensina II y la endotelina 1, ya que en los fibroblastos cardíacos, el ANP y el BNP inhiben los efectos del factor de crecimiento beta ${ }^{31}$. A su vez, la medición de péptidos natriuréticos en plasma se utiliza como método diagnóstico y pronóstico en $\mathrm{IC}^{31-34}$. De todas formas, nunca debe reemplazar al criterio clínico, y siempre debe ser contextuado en el caso de cada paciente, ya que el BNP puede estar elevado en otras patologías tanto cardíacas (valvulopatías, cardiopatía isquémica, arritmias auriculares, hipertensión pulmonar) como extracardíacas (edad, insuficiencia renal, sepsis, tromboembolismo pulmonar) ${ }^{35}$. Más recientemente, se descubrió que existen determinadas situaciones en las cuales sus valores pueden encontrarse normales a pesar de presentar falla cardíaca, conocidos como estados de deficiencia de péptidos natriuréticos, como en la obesidad. La reducción de BNP en esta población podría explicar su mayor susceptibilidad a las enfermedades cardiovasculares. Este efecto se cree debido a que, a pesar de la mayor producción de ANP y BNP por la retención de sodio y el consiguiente aumento del volumen que se da en la obesidad, el tejido adiposo reúne gran cantidad de receptores para la degradación de péptidos natriuréticos ${ }^{36}$.

En estadíos avanzados de insuficiencia cardíaca, debido al procesamiento alterado del BNP de causa aún no aclarada, existe menor cantidad de hormona activa, a pesar de los elevados niveles de BNP inmunorreactivo. Esto es debido al clivaje de precursores inactivos o de menor actividad biológica' hecho que explicaría la falta de actividad fisiológica contrarrestadora de los sistemas compensadores en la IC avanzada, a pesar de los altos niveles registrados de BNP, de los que no se distingue por laboratorio entre formas activas e inactivas del mismo ${ }^{37}$.

A su vez, otra explicación de la elevación del BNP en IC avanzada es la gran activación del SRAA, de manera que reflejan mayor activación de los sistemas vasoconstrictores. Otra es que, a medida que avanza la enfermedad, sus efectos biológicos se pierden por disminución de número de receptores y un fenómeno de desacople de los mismos ${ }^{38}$

\section{D. PÉPTIDOS NATRIURÉTICOS EN EL TRATAMIENTO DE LA INSUFICIENCIA CARDÍACA}

Por su naturaleza contrarreguladora de la insuficiencia cardíaca, han sido varios los intentos en la historia por plasmar su beneficio fisiológico en un fármaco para tratar dicha enfermedad.

Uno de los primeros intentos fue con el candoxatril en 1991, un inhibidor de la neprilisina utilizado como monodroga por vía ora ${ }^{39}$. A principio, se vio un beneficio al aumentar la natriuresis y aumentar los valores plasmáticos de ANP, pero posteriormente se encontró un aumento de los valores de angiotensina II, con los efectos deletéreos que ella produce, por lo cual se discontinuó ${ }^{40}$

Visto que la inhibición de la neprilisina por sí sola no bastaba para batallar la activación neurohormonal en la insuficiencia cardíaca, se decidió combinarla junto con una droga que inhiba el SRAA. Es as como surgió el omapaprilat, un inhibidor dual de la neprilisina y de la enzima convertidora de angiotensina. Se realizaron numerosos ensayos comparando esta droga con los IECA, siendo notable que en uno de ellos se la comparó con enalapril, en el cual no demostró inferioridad respecto al punto primario combinado de muerte $u$ hospitalizaciones ${ }^{41,42}$. Incluso se realizó un estudio randomizado con una población de más de 25 mil participantes para comparar omapaprilat en contra del enalapril en pacientes hipertensos ${ }^{43}$. A pesar de obtener buenos resultados en cuanto al control de la presión arterial a favor del omapaprilat, se observó un aumento del angioedema severo. Se piensa que este efecto se produce porque ambos fármacos generan 
altos niveles de bradiquininas. Dado este efecto adverso tan importante, la Food and Drug Administration (FDA) no aprobó su utilización.

\section{INHIBICIÓN DEL RECEPTOR DE ANGIOTENSINA Y DE LA NEPRILISINA}

En los últimos años se originó una nueva y prometedora combinación de dos fármacos para el tratamiento de la insuficiencia cardíaca: el sacubitril (inhibidor de la neprilisina), con el valsartán (un inhibidor de los receptores de angiotensina II), que se denominó LCZ696. Es el primero de una nueva clase de fármacos para el tratamiento de la insuficiencia cardíaca: inhibidores de los receptores de la angiotensina y de la neprilisina (IRAN). Este doble bloqueo permite actuar en contra del mecanismo neurohormonal, al bloquear al SRAA y aumentar la concentración de péptidos natriuréticos ${ }^{44}$.

Dado que la inhibición de neprilisina es insuficiente para bloquear por sí sola al sistema renina-angiotensina-aldosterona, ya que entre sus sustratos no solo se encuentra la enzima catalizadora de péptidos natriuréticos sino que también degrada péptidos vasoconstrictores como la angiotensina I y |l y la endotelina, entre otros, es que debe ser acompañada simultáneamente con un fármaco que permita bloquear al SRAA. La neprilisina asociada con inhibidores de la enzima convertidora de la angiotensina, como ya hemos visto, demostró aumento del angioedema, de modo que esa combinación no se utilizó. En su lugar, se combinó con un inhibidor de la angiotensina II, el valsartán.

La forma farmacéutica del sacubitril/valsartán son comprimidos recubiertos, disponibles en distintas concentraciones: 50 mg, $100 \mathrm{mg}$ y 200 mg (24 mg sacubitril / 26 mg valsartan, 49 mg sacubitril / 51 mg valsartan, y 97 mg sacubitril / 103 mg valsartan, respectivamente). Si bien la dosis prevista es de $200 \mathrm{mg}$ dos veces al día, se recomienda una dosis inicial de $50 \mathrm{mg}$ dos veces al día en los pacientes que no estén tomando un IECA ni un ARA II, y debe considerarse en el caso de los pacientes que hayan tomado anteriormente dosis bajas de estos fármacos. Se duplicará la dosis cada 2-4 semanas según tolerabilidad del paciente, hasta llegar a la dosis objetivo. Debemos recordar el riesgo aumentado de angioedema con la administración concomitante con un IECA, por lo cual el mismo debe suspenderse 36 horas antes del inicio del tratamiento con sacubitril/valsartán. Si los pacientes presentan problemas de tolerabilidad (hipotensión arterial sintomática, hiperpotasemia, disfunción renal), se debe estudiar la posibilidad de reajustar la dosis. Está contraindicado en embarazadas, en insuficiencia renal crónica con clearance menor a $30 \mathrm{mg} / \mathrm{ml} /$ por 1.73 de metros cuadrados corporales, en pacientes con enfermedad hepática severa y antecedente de angioedema.

Tras la administración oral, el LCZ696 se disocia en: sacubitril, que es metabolizado a AHU377, el cual luego se metaboliza a su vez en LBQ657, su componente activo, inhibidor directo de la neprilisina; y valsartán (Figura 2). Alcanzan concentraciones plasmáticas máximas al cabo de una media de 0,5 horas, 3 horas y 1,5 horas, respectivamente. Se estima que la biodisponibilidad absoluta por vía oral es del 60\% como mínimo en el caso del sacubitril y del 23\% en el caso del valsartán. Las vidas medias del LBQ657 y el valsartán son 12 y 14 horas, respectivamente, permitiendo la administración del fármaco dos veces al día. Con ello, se alcanzan concentraciones de estado estacio-

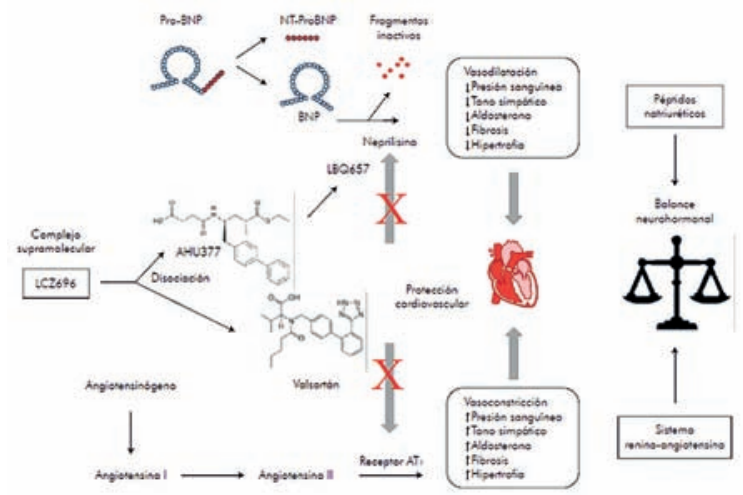

Figura 2. Acción dual de inhibición de la neprilisina y bloqueo del receptor de angiotensina II mediante el LCZ696. La prodroga del sacubitril es el AHU377, que luego se metaboliza a LBQ657, un inhibidor específico de la neprilisina. Se inhiben principalmente las acciones perjudiciales de la angiotensina II, y se potencian los efectos beneficiosos del péptido natriurétiCo, al inhibir la enzima que lo degrada. AT 1: angiotensina I. Pro-BNP: pro péptido natriurético cerebral. BNP: péptido natriurético cerebral. NT-pro-BNP: fragmento aminoterminal de dicha molécula. Modificado de Manzur F, Villarreal T, Moneriz C. Inhibición dual de la neprilisina y el receptor de angiotensina II: nueva estrategia prometedora en el tratamiento de la enfermedad cardiovascular. Rev Colomb Cardiol 2013;20(6):389.

nario de sacubitril, LBQ657 y valsartán al cabo de 3 días. Puede administrarse con o sin alimentos. En cuanto a su distribución, muestra un alto grado de unión a proteínas plasmáticas (94-97\%). Según la comparación entre las concentraciones plasmáticas y las del LCR, el LBQ657 atraviesa la barrera hematoencefálica en grado limitado $(0,28 \%)$. Respecto al metabolismo, el sacubitril se biotransforma rápidamente en LBQ657 por la acción de esterasas, que no se metaboliza en grado significativo. El valsartán se metaboliza en grado mínimo, ya que apenas el 20\% de la dosis, aproximadamente, se recupera en forma de metabolitos. En cuanto a su eliminación, tras la administración oral, entre el $52 \%$ y el $68 \%$ del sacubitril (principalmente en forma de LBQ657), y aproximadamente el 13\% del valsartán y sus metabolitos se excretan en la orina; entre el $37 \%$ y el $48 \%$ del sacubitril (principalmente en forma de LBQ657) y el 86\% del valsartán y sus metabolitos se excretan en las heces. El sacubitril, el LBQ657 y el valsartán se eliminan del plasma con una vida media de eliminación que ronda en las 1,43 horas, 11,48 horas y 9,90 horas, respectivamente ${ }^{45}$.

\section{EVIDENCIA ACTUAL}

Recientemente se publicó el estudio PARADIGM-HF ${ }^{46}$, ensayo clínico prospectivo que demostró que este nuevo fármaco disminuye la mortalidad significativamente, comparado con un inhibidor de la enzima convertidora de angiotensina, el enalapril. En este ensayo clínico randomizado se seleccionaron 8442 pacientes (Tabla 1) con insuficiencia cardíaca con fracción de eyección disminuida (FEy menor a 40\%), y luego por una enmienda, menor a 35\%, en clase funcional según la escala de New York Heart Association (NYHA) II a IV (la mayoría de los participantes se encontraban en clase funcional II), con valor de BNP igual o mayor a 150 picogramos por mililitro (pg/ml), o NTproBNP igual o mayor a $600 \mathrm{pg} / \mathrm{ml}$, o si estuvieron hospitalizados por insuficiencia cardíaca los doce meses previos, igual o mayor a 100 pg/ $\mathrm{ml}$, o igual o mayor a $400 \mathrm{pg} / \mathrm{ml}$, respectivamente. Los criterios de exclusión fueron: pacientes hipotensos (TAS $<90 \mathrm{mmHg}$ ), con deterioro de la función renal (clearance de creatinina menor a $30 \mathrm{ml} /$ minuto/ 
Tabla 1. Características basales de los pacientes incluidos en el PARADIGM-HF.

\begin{tabular}{|c|c|c|}
\hline Características & $\begin{array}{c}\text { LCZ696 } \\
(\mathrm{N}=4187)\end{array}$ & $\begin{array}{l}\text { Enalapril } \\
(\mathrm{N}=4212)\end{array}$ \\
\hline Edad & $63,8 \pm 11,5$ & $63,8 \pm 11,3$ \\
\hline Sexo femenino & $879(21,0)$ & $953(22,6)$ \\
\hline \multicolumn{3}{|l|}{ Raza o grupo étnico } \\
\hline $\begin{array}{l}\text { Blanco } \\
\text { Negro } \\
\text { Asiático } \\
\text { Otro }\end{array}$ & $\begin{array}{l}2763(66,0) \\
213(5,1) \\
759(18,1) \\
452(10,8)\end{array}$ & $\begin{array}{l}2781(66,0) \\
215(5,1) \\
750(17,8) \\
466(11,1)\end{array}$ \\
\hline \multicolumn{3}{|l|}{ Región - N (\%) } \\
\hline $\begin{array}{l}\text { Norteamérica } \\
\text { América latina } \\
\text { Europa del Este } \\
\text { Europa Central } \\
\text { Asiáticos y del Pacífico }\end{array}$ & $\begin{array}{c}310(7,4) \\
713(17,0) \\
1026(24,5) \\
1393(33,3) \\
745(17,8)\end{array}$ & $\begin{array}{c}292(6,9) \\
720(17,1) \\
1025(24,3) \\
1433(34,0) \\
742(17,6)\end{array}$ \\
\hline Presión arterial sistólica (mmHg) & $122 \pm 15$ & $121 \pm 15$ \\
\hline Frecuencia cardíaca (latidos/minuto) & $72 \pm 12$ & $73 \pm 12$ \\
\hline Índice de masa corporal & $28 \pm 5,5$ & $28,2 \pm 5,5$ \\
\hline Creatinina sérica (mg/ml) & $1,13 \pm 0,3$ & $1,12 \pm 0,3$ \\
\hline \multicolumn{3}{|c|}{ Características técnicas de la insuficiencia cardíaca } \\
\hline $\begin{array}{l}\text { Cardiopatía isquémica - N (\%) } \\
\text { Fracción de eyección del VI (\%) } \\
\text { Media de BNP (pg/ml) } \\
\text { Media de NT-proBNP (pg/ml) }\end{array}$ & $\begin{array}{c}2506(59,9) \\
29,6 \pm 6.1 \\
255(155-474) \\
1631(885-3154)\end{array}$ & $\begin{array}{c}2530(60,1) \\
29,4 \pm 6,3 \\
251(153-465) \\
1594(886-3305)\end{array}$ \\
\hline \multicolumn{3}{|l|}{ Clase funcional de la NYHA - N (\%) } \\
\hline $\begin{array}{l}\text { I } \\
\text { II } \\
\text { III } \\
\text { IV }\end{array}$ & $\begin{array}{c}180(4,3) \\
2998(71,6) \\
969(23,1) \\
33(0,8)\end{array}$ & $\begin{array}{c}209(5,0) \\
2921(69,3) \\
1049(24,9) \\
27(0,6)\end{array}$ \\
\hline Datos perdidos & $7(0,2)$ & $6(0,1)$ \\
\hline \multicolumn{3}{|l|}{ Antecedentes (ํo y \%) } \\
\hline $\begin{array}{l}\text { Hipertensión arterial } \\
\text { Diabetes } \\
\text { Fibrilación auricular } \\
\text { Hospitalización por falla cardíaca } \\
\text { Infarto de miocardio } \\
\text { Accidente cerebrovascular } \\
\text { Uso previo de IECA } \\
\text { Uso previo de ARA II } \\
\text { Diuréticos } \\
\text { Digitálicos } \\
\text { Betabloqueantes } \\
\text { Antagonistas de los mineralocorticoides } \\
\text { Cardiodesfibrilador implantable } \\
\text { Terapia de resincronización cardíaca }\end{array}$ & $\begin{array}{l}2969(70,9) \\
1451(34,7) \\
1517(36,2) \\
2607(62,3) \\
1818(43,4) \\
355(8,5) \\
3266(78,0) \\
929(22,2) \\
3363(80,3) \\
1223(29,2) \\
3899(93,1) \\
2271(54,2) \\
623(14,9) \\
292(7,0)\end{array}$ & $\begin{array}{l}2971(70,5) \\
1456(34,6) \\
1574(37,4) \\
2667(63,3) \\
1816(43,1) \\
370(8,8) \\
3266(77,5) \\
963(22,9) \\
3375(80,1) \\
1316(31,2) \\
3912(92,9) \\
2400(57,0) \\
620(14,7) \\
282(6,7)\end{array}$ \\
\hline
\end{tabular}

VI: ventrículo izquierdo. BNP: péptido natriurético cerebral. NYHA: escala de disnea de la New York Heart Association. IECA: inhibidores de la enzima convertidora de angiotensina. ARA II: inhibidores de receptores de angiotensina II. Modificado de McMurray JJ, Packer M, Desai AS, Gong J, Lefkowitz MP, Rizkala AR, et al. Angiotensin-neprilysin inhibition versus enalapril in heart failure. N Engl J Med 2014;371(11):993-1004.

por 1,73 de metros cuadrados corporales), con hiperkalemia (potasio sérico $>5,4 \mathrm{mEq} / \mathrm{ll}$ ). Y los de inclusión: pacientes que estén recibiendo $10 \mathrm{mg} /$ día de enalapril bien tolerados. El promedio de edad fue de 64 años, con mayoría de hombres, y mayoría de pacientes en CF II y III, alta prevalencia de pacientes con diabetes y fibrilación auricular, correctamente medicados con el tratamiento estándar para IC.

El punto final primario fue un compuesto de muerte por causa cardiovascular o primera hospitalización por insuficiencia cardíaca. Los puntos finales secundarios fueron muerte por cualquier causa, un cambio en la clínica desde el basal hasta los 8 meses de seguimiento medido por un score norteamericano (the Kansas City Cardiomyopathy
Questionnaire -KCCQ-), aparición de fibrilación auricular y falla renal (que fue definido como estadio final de la enfermedad renal, o como una caída del filtrado glomerular de más de $30 \mathrm{ml} /$ minuto/por 1,73 de metros cuadrados corporales). Respecto del análisis estadístico, estimaron que el promedio anual del punto final primario sería del $14,5 \%$, y el promedio de muerte por causas cardiovasculares sería del 7,0\% en el grupo del enalapril, con lo cual el cálculo de la muestra les arrojó que necesitaban seguir a 8000 pacientes durante 34 meses, con 1229 muertes por causa cardiovascular, para que el estudio posea un poder del $80 \%$ y detectar un reducción relativa del 15\% de riesgo de muerte por causa cardiovascular en el grupo con LCZ696, con un valor de alfa de 0,05.

Constó de dos fases, la primera fue la de run in en 9419 pacientes, en la que se probó el enalapril a dosis de 10 mg dos veces al día durante dos semanas, seguido de un día sin fármaco, para luego probar el LCZ696 durante dos semanas más (primero 100 mg cada 12 horas, luego 200 mg cada 12 horas), para así excluir del estudio a los pacientes que presentaban efectos adversos (hipotensión, hiperkalemia, faIla renal). Finalizados los tamizajes, los pacientes fueron randomizados en dos grupos para recibir el compuesto LCZ696 (200 mg, dos veces al día) o enalapril (10 mg, dos veces al día), respectivamente, más el tratamiento estándar de insuficiencia cardíaca, con betabloqueantes y antagonistas de la aldosterona.

El estudio fue detenido a los 27 meses por el comité de ética debido a la reducción significativa de la mortalidad a favor del LCZ696. Como resultados, este estudio mostró significancia estadística a favor del grupo con LCZ696 por disminuir el punto final primario combinado de muerte por causa cardiovascular o primera hospitalización por insuficiencia cardíaca descompensada, y a su vez, en el subanálisis posterior de cada punto por separado, y de los puntos finales secundarios, la reducción de la mortalidad por cualquier causa (Tabla 2

y Figura 3). Como conclusiones de este estudio, se pudo desprender que el tratamiento con inhibición dual de la neprilisina y del receptor de angiotensina II, con sacubitril/valsartán, redujo significativamente la mortalidad total y de causa cardiovascular, y menor hospitalización, comparado con enalapril. Respecto a los efectos adversos, la hipotensión, tanto sintomática como asintomática, fue significativamente más frecuente en el grupo tratado con LCZ696, y la tos, en el de enalapril. Otros eventos adversos, como la elevación de los niveles de creatinina, angioedema, hiperkalemia, no mostraron diferencias estadísticamente significativas entre ambos grupos.

Un análisis posterior sobre el riesgo de progresión clínica de la IC en pacientes tratados con enalapril o LCZ696 concluyó que el LCZ696 también muestra beneficio frente al enalapril, mostrando significancia estadística en la disminución de las internaciones por insuficiencia cardíaca descompensada, y en la disminución del valor del NTproBNP a favor del LCZ696 (Figura 4) ${ }^{47}$

Posteriormente, se llevó a cabo un estudio doble ciego y randomizado diseñado para la titulación de dosis de LCZ696 en 498 pacientes con FEy menor al 35\% durante un período designado de seguimiento de 12 semanas. Para su análisis, los pacientes fueron estratificados según tolerancia a dichos fármacos, en el estrato alto, a aquellos que toleraban más de $10 \mathrm{mg} /$ día de enalapril, o más de 160 mg/día de valsartán, o su dosis equivalente de otro IECA/ARAll 
Tabla 2. Resultados de los puntos finales primarios y secundarios del PARADIGM-HF.

\begin{tabular}{|c|c|c|c|c|}
\hline Resultado & $\begin{array}{c}\text { LCZ696 } \\
(\mathrm{N}=4187)\end{array}$ & $\begin{array}{l}\text { Enalapril } \\
(\mathrm{N}=4212)\end{array}$ & $\begin{array}{l}\text { Hazard ratio } \\
\text { (IC95\%) }\end{array}$ & Valor de $p$ \\
\hline \multicolumn{5}{|l|}{ Resultado primario compuesto - N (\%) } \\
\hline $\begin{array}{l}\text { Muerte por causa cardiovascular o primera hospitalización por empeoramiento de la IC } \\
\text { Muerte por causa cardiovascular } \\
\text { Primera hospitalización por empeoramiento de la IC }\end{array}$ & $\begin{array}{l}914(21,8) \\
558(13,3) \\
537(12,8)\end{array}$ & $\begin{array}{l}1117(26,5) \\
693(16,5) \\
658(15,6)\end{array}$ & $\begin{array}{l}0,80(0,73-0,87) \\
0,80(0,71-0,89) \\
0,79(0,71-0,89)\end{array}$ & $\begin{array}{l}<0,001 \\
<0,001 \\
<0,001\end{array}$ \\
\hline \multicolumn{5}{|l|}{ Resultados secundarios - N (\%) } \\
\hline $\begin{array}{l}\text { Muerte por cualquier causa } \\
\text { Cambio en el cuestionario KCCQ } \\
\text { Aparición de fibrilación auricular } \\
\text { Empeoramiento de la función renal }\end{array}$ & $\begin{array}{c}711(17,0) \\
-2,99 \pm 0,36 \\
84(3,1) \\
94(2,2)\end{array}$ & $\begin{array}{c}835(19,8) \\
-4,62 \pm 0,36 \\
83(3,1) \\
108(2,6)\end{array}$ & $\begin{array}{l}0,84(0,76-0,93) \\
1,64(0,63-2,65) \\
0,97(0,72-1,31) \\
0,86(0,65-1,13)\end{array}$ & $\begin{array}{c}<0,001 \\
0,001 \\
0,83 \\
0,28\end{array}$ \\
\hline
\end{tabular}

IC: insuficiencia cardíaca. KCCQ: Kansas city cardiomyopathy questionnaire. Modificado de MCMurray JJ, Packer M, Desai AS, Gong J, Lefkowitz MP, Rizkala AR, et al. Angiotensin-neprilysin inhibition versus enalapril in heart failure. N Engl J Med 2014;371(11):993-1004.
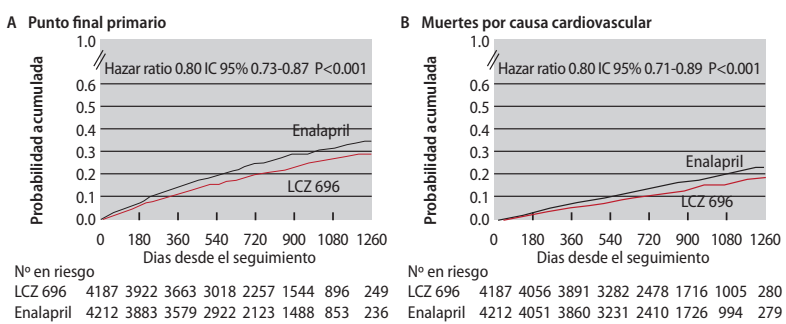

LCZ $696418739223663301822571544896249 \quad$ LCZ $696 \quad 4187405638913282247817161005280$ C Hospitalizaciones por insuficiencia cardíaca

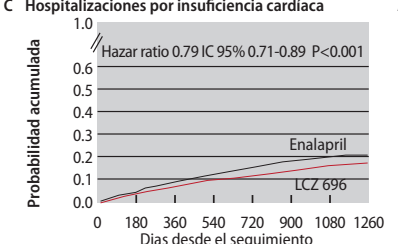

$\begin{array}{llllllll}0 & 180 & 360 & 540 & 720 & 900 & 1080 & 1260\end{array}$

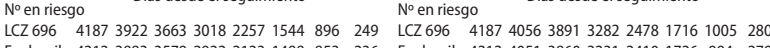
Enalapril $421238833579292221231488 \quad 853 \quad 236 \quad$ Enalapril 421240513860323124101726994279

Figura 3. Curvas de Kaplan y Meier para los puntos finales del estudio PARADIGM-HF.IC: intervalo de confianza. Modificado McMurray JJ, Packer M, Desai AS, Gong J, Lefkowitz MP, Rizkala AR, et al. Angiotensin-neprilysin inhibition versus enalapril in heartfailure. N Engl J Med 2014;371 (11):993-1004.

y en el estrato bajo, a aquellos que toleraban menos de eso, con una relación 1:1 en dicho estudio (Tabla 3). Después de un período de run in de 5 días en el cual todos los pacientes recibieron 50 mg cada 12 horas de LCZ696 (habiendo suspendido IECA/ARAll 36 horas antes), se los dividió en dos grupos, un grupo para titulación conservadora ( $n=251$ ), que siguieron con 50 mg dos veces por día por dos semanas, 100 dos veces por día por seis semanas, y luego 200 mg dos veces por día, y otro para titulación rápida ( $n=247$ ), que pasaron de $50 \mathrm{mg}$ dos veces por día a $200 \mathrm{mg}$ dos veces por día cada tres semanas, durante un período total de seguimiento de 11 semanas. Como puntos finales primarios, el estudio se propuso testear la ocurrencia de efectos adversos: hipotensión sintomática, hiperkalemia, insuficiencia renal y angioedema entre ambos grupos, obteniendo como resultado diferencias sin significancia estadística, con mayor ocurrencia de los mismos en el grupo de titulación rápida. Los puntos finales secundarios fueron: 1) éxito del tratamiento, definido como la proporción de pacientes en los dos grupos de tratamiento que lograran alcanzar y mantener una dosis de sacubitril/valsartán de 200 mg dos veces por día sin bajar o suspender el fármaco durante doce semanas; 2) éxito de tolerabilidad, definido como la proporción de pacientes, excluyendo a los pacientes que discontinuaron el tratamiento por razones diferentes a efectos adversos o muerte, que toleraran una dosis de sacubitril/valsar-
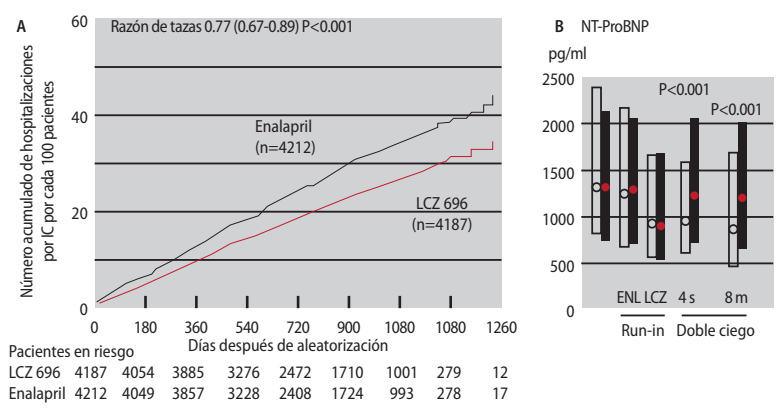

Figura 4. A. Número acumulado de hospitalizaciones por insuficiencia cardíaca en los pacientes tratados con enalapril comparado con los tratados por LCZ696. B. La mediana obtenida de los valores de N-terminal pro-BNP al ingreso y durante el estudio. Los pacientes en el grupo de LCZ696 se encuentran representados por barras blancas, y los pacientes en el grupo de enalapril por las barras grises. NT-pro-BNP: Fragmento aminoterminal de la molécula del pro-péptido natriurético cerebral. Modificado de Packer M, McMurray J, Desai AS, Gong J, Lefkowitz MP, Rizkala AR, et al. Angiotensin receptor neprilysin inhibition compared with enalapril on the risk of clinical progression in surviving patients with heart failure. Circulation 2015;131(1):54-61

tán de 200 mg dos veces por día por al menos las dos últimas semanas permitiendo completar el estudio, a pesar de previa disminución o interrupción del tratamiento. Como resultado, un 75,9\% de los pacientes alcanzaron el éxito terapéutico, y un 79,7\% alcanzó la tolerabilidad. Cuando examinaron estos dos resultados acorde a los estratos alto y bajo según tolerancia a IECA/ARA II, se encontró que alcanzaron el éxito terapéutico en mayor medida los del estrato bajo ${ }^{48}$

Posteriormente se realizó un estudio en base al PARADIGM-HF para saber el verdadero riesgo de los pacientes enrolados en dicho estudio utilizando el score MAGGIC como marcador pronóstico, y el efecto del LCZ696 para reducirlo, analizando en base a los puntos finales de dicho estudio. Respecto al puntaje de cada paciente y su categorización en el estudio, la mediana fue de 20, con un rango intercuartilo de 16-24, y puntajes desde 4 a 40 (Figura 5). Como resultados, cada 1 punto de aumento en el score se asoció a un aumento del $6 \%$ del riesgo para producir el punto final primario, con una diferencia estadísticamente significativa. En cuanto al efecto del LC696 respecto a ese riesgo, se observó que el efecto del tratamiento fue mayor en los pacientes con puntuaciones más altas de riesgo. Por ejemplo, aplicando la reducción del riesgo proporcional con LCZ696 (en comparación con enalapril) a los pacientes del quintilo 5 (con puntuaciones de riesgo de 26-40 puntos), representaría que 8 pacientes menos presenten los eventos del punto final primario, recibiendo el trata- 
Tabla 3. Características basales de los pacientes incluidos en el estudio TITRATION.

\begin{tabular}{|c|c|c|c|c|c|}
\hline \multirow[b]{2}{*}{ Demografía } & \multicolumn{2}{|c|}{ Titulación } & \multicolumn{2}{|c|}{ Estrato IECA/ARA II } & \multirow{2}{*}{$\begin{array}{c}\text { Total } \\
(\mathrm{n}=498)\end{array}$} \\
\hline & Rápida (n=247) & Conservadora $(n=251)$ & Alto $(n=247)$ & Bajo $(n=251)$ & \\
\hline Edad media (DS) & $64,2(11,86)$ & $63,8(10,94)$ & $63,1(12,10)$ & $64,9(10,60)$ & $64,0(11,39)$ \\
\hline Género masculino & $191(77,3)$ & $201(80,1)$ & $196(79,4)$ & $196(78,1)$ & $392(78,7)$ \\
\hline \multicolumn{6}{|l|}{ Raza predominante (\%) } \\
\hline $\begin{array}{l}\text { Caucásicos } \\
\text { Negros } \\
\text { Otra }\end{array}$ & $\begin{array}{c}228(92,3) \\
12(4,9) \\
7(2,8)\end{array}$ & $\begin{array}{c}234(93,2) \\
11(4,4) \\
6(2,4)\end{array}$ & $\begin{array}{c}224(90,7) \\
12(4,9) \\
11(4,5)\end{array}$ & $\begin{array}{c}238(94,8) \\
11(4,4) \\
2(0,8)\end{array}$ & $\begin{array}{c}462(92,8) \\
23(4,6) \\
13(2,6)\end{array}$ \\
\hline \multicolumn{6}{|l|}{ Composición de los pacientes. N (\%) } \\
\hline $\begin{array}{l}\text { Hospitalizados } \\
\text { Ambulatorios } \\
\text { Altas dosis IECA/ARAll } \\
\text { Bajas dosis IECA/ARAll } \\
\text { Dosis inocente/sin IECA/ARAll }\end{array}$ & $\begin{array}{c}25(10,1) \\
222(89,9) \\
120(48,6) \\
127(51,4) \\
17(6,9)\end{array}$ & $\begin{array}{c}31(12,4) \\
220(87,6) \\
127(50,6) \\
124(49,4) \\
16(6,4)\end{array}$ & $\begin{aligned} & 17(6,9) \\
& 230(93,1) \\
&- \\
&-- \\
&-\end{aligned}$ & $\begin{array}{c}39(15,5) \\
212(84,5) \\
- \\
- \\
-\end{array}$ & $\begin{array}{c}56(11,2) \\
442(88,8) \\
247(49,6) \\
251(50,4) \\
33(6,6)\end{array}$ \\
\hline FEy basal (\%) - media (DS) & $29,8(5,15)$ & $29,6(5,36)$ & $30,5(5,08)$ & $28,9(5,32)$ & $29,7(5,25)$ \\
\hline \multicolumn{6}{|l|}{ Clave NYHA en el screening - N (\%) } \\
\hline $\begin{array}{l}\text { II } \\
\text { III } \\
\text { IV }\end{array}$ & $\begin{array}{c}175(70,9) \\
72(29,1) \\
0(0,0)\end{array}$ & $\begin{array}{c}178(70,9) \\
72(28,7) \\
1(0,4)\end{array}$ & $\begin{array}{c}191(77,3) \\
56(22,7) \\
0(0,0)\end{array}$ & $\begin{array}{c}162(64,5) \\
88(35,1) \\
1(0,4)\end{array}$ & $\begin{array}{c}353(70,9) \\
144(28,9) \\
1(0,2)\end{array}$ \\
\hline Indice de masa corporal (kg/m²) en el screening - media (DE) & $30,9(5,88)$ & $30,6(6,03)$ & $31,6(6,10)$ & $30,0(7,70)$ & $30,8(5,95)$ \\
\hline Tensión arterial sistólica (mmHg) en la $2^{\circ}$ visita - media (DE) & $130,8(16,64)$ & $130,8(15,98)$ & $132,7(16,91)$ & $129,0(15,49)$ & $130,8(16,30)$ \\
\hline Tensión arterial diastólica (mmHg) en la $2^{\circ}$ visita - media (DE) & $77,2(9,99)$ & $77,6(9,26)$ & $78,0(9,34)$ & $76,8(9,87)$ & $77,4(9,62)$ \\
\hline Filtrado glomerular basal (ml/min1,73 m²) - media (DE) & $69,6(21,63)$ & $70,6(25,16)$ & $71,4(21,85)$ & $68,8(24,90)$ & $70,1(23,45)$ \\
\hline \multicolumn{6}{|l|}{ Filtrado glomerular basal (ml/min1,73 m²) - $\mathrm{n}(\%)$} \\
\hline $\begin{array}{l}<60 \\
\geq 60\end{array}$ & $\begin{array}{c}83(33,6) \\
163(66,0)\end{array}$ & $\begin{array}{c}85(33,9) \\
164(65,3)\end{array}$ & $\begin{array}{c}73(29,6) \\
173(70,0)\end{array}$ & $\begin{array}{c}95(37,8) \\
154(61,4)\end{array}$ & $\begin{array}{l}168(33,7) \\
327(65,7)\end{array}$ \\
\hline
\end{tabular}

NYHA: escala de disnea de la New York Heart Association. IECA: inhibidores de la enzima convertidora de angiotensina. ARA Il: Inhibidores del receptor de angiotensina II. FEy: Fracción de eyección.. Modificado de Senni M, McMurray JJ, Wachter R, McIntyre HF, Reyes A, Majercak I, et al. Initiating sacubitril/valsartan (LCZ696) in heart failure: results of TITRATION, a double-blind, randomized comparison of two uptitration regimens. Eur J Heart Fail 2016;18(9):1193-1202

A

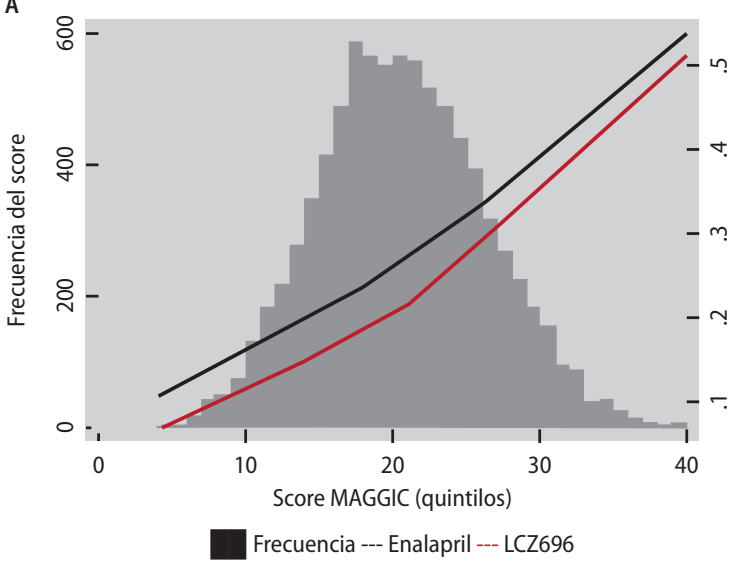

Figura 5. Distribución del riesgo de cada paciente según el score MAGGIC, dividido en quintilos, y su asociación con la posibilidad de alcanzar los puntos finales del PARADIGM-HF, con enalapril o LCZ696. Modificado de Simpson J, Jhund PS, Silva Cardoso J, Martinez F, Mosterd A, Ramires F, et al. Comparing LCZ696 With Enalapril According to Baseline Risk Using the MAG GIC and EMPHASIS-HF Risk Scores: An Analysis of Mortality and Morbidity in PARADIGM-HF. $J$ Am Coll Cardiol 2015;66(19):2059-2071

miento durante dos años, respecto a 4 de 100 pacientes del quintilo 1 (415) (Tabla 4 y Figura 6) ${ }^{49}$.

En 2015 se aprobó el LCZ696 por la FDA para el tratamiento de la insuficiencia cardíaca con fracción de eyección reducida ${ }^{50}$.

Al ser un fármaco nuevo, de reciente incorporación en la práctica clínica, aún permanecen poco dilucidados ciertos problemas de seguridad. Teóricamente, podría incrementar el riesgo de enfermedad de
Alzheimer ${ }^{51}$. A pesar de que aún no se conoce por completo la fisiopatología de esta enfermedad, se sabe que la proteína beta amiloidea participa en ella, y la misma es un sustrato de la neprilisina, con lo cual existe la hipótesis de que este fármaco generaría mayor generación y acumulación de placas amiloideas a nivel cerebral. Dado que el desarrollo de esta enfermedad en general es a largo plazo, desconocemos si este fármaco podría estar relacionado con su desarrollo, además de que el deterioro cognitivo no fue evaluado en el ensayo clínico del fármaco². Actualmente, se está llevando a cabo un nuevo estudio con sacubitril/valsartán en IC con FEy conservada, en el cual se incluye el análisis de la función cognitiva ${ }^{53}$.

\section{INDICACIONES}

El sacubitril/valsartán se recomienda como reemplazo de los IECA para reducir aún más el riesgo de muerte y hospitalizaciones por insuficiencia cardíaca, en pacientes ambulatorios, con fracción de eyección deteriorada, que persisten sintomáticos a pesar de tratamiento óptimo con IECA, betabloqueantes y un antagonista de los mineralocorticoides. Esta indicación es de clase I con nivel de evidencia B2,354.

\section{DISCUSIÓN}

Hemos realizado una revisión de la fisiopatología de la IC, con el sistema neurohormonal del SRAA como regulador y el sistema de péptidos natriuréticos como contrarregulador, permitiendo introducirnos al desarrollo de un nuevo fármaco, el sacubitril/valsartán, que actúa 


\begin{tabular}{|c|c|c|c|c|c|c|c|c|c|c|c|}
\hline \multirow[b]{3}{*}{ Resultado } & & \multicolumn{10}{|c|}{ Categoría de riesgo (puntos) } \\
\hline & & \multicolumn{2}{|c|}{$4-15(n=1762)$} & \multicolumn{2}{|c|}{$1618(n=1,637)$} & \multicolumn{2}{|c|}{$19-21(n=1,675)$} & \multicolumn{2}{|c|}{$22-25(n=1,842)$} & \multicolumn{2}{|c|}{$26-40(n=1459)$} \\
\hline & & $\begin{array}{l}\text { Enalapril } \\
(\mathrm{n}=859)\end{array}$ & $\begin{array}{l}\text { LCZ696 } \\
(n=903)\end{array}$ & $\begin{array}{l}\text { Enalapril } \\
(n=823)\end{array}$ & $\begin{array}{l}\text { LCZ696 } \\
(n=814)\end{array}$ & $\begin{array}{l}\text { Enalapril } \\
(n=865)\end{array}$ & $\begin{array}{l}\text { LCZ696 } \\
(n=810)\end{array}$ & $\begin{array}{l}\text { Enalapril } \\
(n=937)\end{array}$ & $\begin{array}{l}\text { LCZ696 } \\
(n=905)\end{array}$ & $\begin{array}{l}\text { Enalapril } \\
(\mathrm{n}=717)\end{array}$ & $\begin{array}{l}\text { LCZ696 } \\
(n=742)\end{array}$ \\
\hline $\begin{array}{l}\text { Muerte cardiovascular } \\
\text { u hospitalización }\end{array}$ & $\begin{array}{c}n \\
\operatorname{Rate}^{*}(95 \% \mathrm{Cl}) \\
\text { HR }(95 \% \mathrm{Cl})\end{array}$ & $\begin{array}{c}143 \\
7,6(6,4-8,9) \\
0,80(0,63-1,02)\end{array}$ & $\begin{array}{c}123 \\
6,1(5,1-7,3) \\
-\end{array}$ & $\begin{array}{c}203 \\
12,0(10,5-13,8) \\
0,69(0,56-0,86)\end{array}$ & $\begin{array}{c}145 \\
8,3(7,0-9,7) \\
-\end{array}$ & $\begin{array}{c}234 \\
13,6(11,9-15,4) \\
0,75(0,62-0,92)\end{array}$ & $\begin{array}{c}171 \\
10,2(8,8-11,8) \\
-\end{array}$ & $\begin{array}{c}263 \\
14,2(12,6-16,3) \\
0,89(0,74-1,06)\end{array}$ & $\begin{array}{c}230 \\
12,5(11,0-14,3) \\
-\end{array}$ & $\begin{array}{c}273 \\
20,618,3-23,20 \\
0,84(0,71-1,00)\end{array}$ & $\begin{array}{c}243 \\
17,2(15,2-19,5) \\
-\end{array}$ \\
\hline Muerte cardiovascular & $\begin{array}{c}n \\
\operatorname{Rate}^{*}(95 \% \mathrm{Cl}) \\
\text { HR }(95 \% \mathrm{Cl})\end{array}$ & $\begin{array}{c}79 \\
4,0(3,2-5,0) \\
0,90(0,65-1,23)\end{array}$ & $\begin{array}{c}75 \\
3,6(2,9-4,5) \\
-\end{array}$ & $\begin{array}{c}111 \\
6,0(5,0-7,3) \\
0,82(0,62-1,09)\end{array}$ & $\begin{array}{c}91 \\
5,0(4,0-6,1) \\
-\end{array}$ & $\begin{array}{c}146 \\
7,7(6,6-9,1) \\
0,68(0,52-0,88)\end{array}$ & $\begin{array}{c}94 \\
5,3(4,3-6,4) \\
-\end{array}$ & $\begin{array}{c}174 \\
8,7(7,5-10,1) \\
0,84(0,67-1,05)\end{array}$ & $\begin{array}{c}145 \\
7,3(6,2-8,6) \\
-\end{array}$ & $\begin{array}{c}182 \\
12,2(10,5-14,1) \\
0,80(0,65-0,99)\end{array}$ & $\begin{array}{c}153 \\
9,7(8,3-11,4) \\
-\end{array}$ \\
\hline $\begin{array}{l}\text { Hospitalización por } \\
\text { insuficiencia cardíaca }\end{array}$ & $\begin{array}{c}n \\
\operatorname{Rate}^{*}(95 \% \mathrm{Cl}) \\
\text { HR }(95 \% \mathrm{Cl})\end{array}$ & $\begin{array}{c}83 \\
4,4(3,6-5,5) \\
0,74(0,53-1,02)\end{array}$ & $\begin{array}{c}66 \\
3,3(2,6-4,2) \\
-\end{array}$ & $\begin{array}{c}128 \\
7,6(6,4-9,0) \\
0,53(0,40-0,71)\end{array}$ & $\begin{array}{c}70 \\
4,0(3,2-5,1) \\
-\end{array}$ & $\begin{array}{c}134 \\
7,8(6,6-9,2) \\
0,78(0,61-1,02)\end{array}$ & $\begin{array}{c}102 \\
6,1(5,0-7,4) \\
-\end{array}$ & $\begin{array}{c}146 \\
7,9(6,7-9,3) \\
0,97(0,77-1,22)\end{array}$ & $\begin{array}{c}139 \\
7,6(6,4-8,9) \\
-\end{array}$ & $\begin{array}{c}167 \\
12,6(10,8-14,7) \\
0,89(0,72-1,11)\end{array}$ & $\begin{array}{c}158 \\
11,1(9,6-13,1) \\
-\end{array}$ \\
\hline $\begin{array}{l}\text { Todas las causas } \\
\text { demuerte }\end{array}$ & $\begin{array}{c}n \\
\operatorname{Rate}^{*}(95 \% \mathrm{Cl}) \\
\text { HR }(95 \% \mathrm{Cl})\end{array}$ & $\begin{array}{c}105 \\
5,3(4,4-6,4) \\
0,86(0,65-1,13)\end{array}$ & $\begin{array}{c}95 \\
4,5(3,7-5,5) \\
-\end{array}$ & $\begin{array}{c}124 \\
6,7(5,6-8,0) \\
0,84(0,65-1,09)\end{array}$ & $\begin{array}{c}104 \\
5,7(4,7-6,9) \\
-\end{array}$ & $\begin{array}{c}168 \\
8,9(7,7-10,4) \\
0,79(0,63-1,00)\end{array}$ & $\begin{array}{c}126 \\
7,1(5,9-8,4) \\
-\end{array}$ & $\begin{array}{c}207 \\
10,3(9,0-11,8) \\
0,92(0,76-1,12)\end{array}$ & $\begin{array}{c}190 \\
9,5(8,3-11,0) \\
-\end{array}$ & $\begin{array}{c}230 \\
15,4(13,5-17,5) \\
0,80(0,66-0,97)\end{array}$ & $\begin{array}{c}194 \\
12,3(10,7-14,2) \\
-\end{array}$ \\
\hline
\end{tabular}

Mortality and Morbidity in PARADIGM-HF JAm Coll Gardiol 2015:66 (19):2059-2071

sobre este sistema neurohormonal, inhibiendo los receptores de la angiotensina y de la neprilisina ${ }^{44}$.

Sin dudas, la introducción de un nuevo fármaco no está exenta de elogios y críticas. En primer lugar, hay varios aspectos para destacar respecto al diseño del PARADIGM-HF. Un punto muy importante es el número de pacientes que incluyó. Gracias al elevado valor de la muestra para demostrar reducción de muerte cardiovascular que se propuso, y que logró, es que demostró tener un alto poder estadístico. Otro hecho es que se propuso comparar este nuevo fármaco con el enalapril, la piedra angular en el tratamiento de la insuficiencia cardíaca, y no con un placebo, y con la dosis en la que se comprobó que dicho fármaco disminuyó la mortalidad en la IC, en los históricos SOLVD y CONSENSUS. Este hecho le confiere gran validez interna al estudio. Pero al ganar en este punto, perdió en validez externa, debido a que la población estudiada no representó al gran universo de los pacientes con IC con los que nos enfrentamos, que no toleran dichas dosis. Como defensa al PARADIGM-HF, como pudimos observar en el trabajo y en las tablas, la mayoría de los participantes se encontraba en clase funcional (CF) II, y sólo una minoría, en CF IV, que son los pacientes que no toleran la dosis máxima en la práctica clínica, y que al remitirnos a los estudios con enalapril de hace casi 30 años, la población es estadísticamente similar en cuanto a clase funcional (la mayoría se encontraba en CF II) y tolerancia de la dosis máxima de enalapril.

Como críticas al PARADIGM-HF surgen en primer lugar el período de run in, por seleccionar a los pacientes, y de esa manera excluir a todos aquellos que pudieran presentar efectos adversos y a los intolerantes a altas dosis de enalapril. En contraposición a esta crítica, es que el TITRATION, como ya hemos expuesto, realizó un estudio con pacientes tratados con o sin IECA/ARAll, y a su vez, subdivididos en aquellos que toleraban dosis altas o bajas. En el mismo, no se encontraron diferencias estadísticamente significativas entre ambos grupos, ni entre los regímenes de titulación ${ }^{48}$.

Con respecto al CONSENSUS y al SOLVD, debemos aclarar que fueron realizados hace casi tres décadas, cuando el tratamiento de la insuficiencia cardíaca, y los afectados por ella, eran completamente distintos: la mayoría de los pacientes estaban tratados con digoxina y diuréticos, aún no se contaba con betabloqueantes ni con antagonistas de los mineralocorticoides, como contamos actualmente, y que sí recibió la población del PARADIGM-HF. Aun así, la rama tratada con sacubitril/valsartán demostró disminución de la mortalidad frente a la rama tratada con enalapril ${ }^{5-7}$.
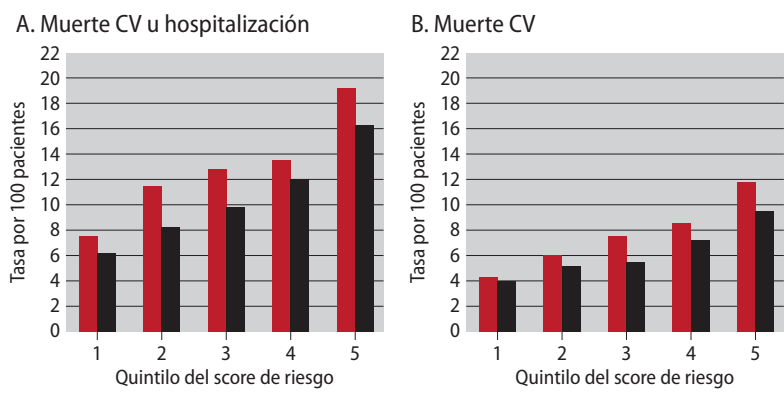

C. Hospitalizaciones por IC

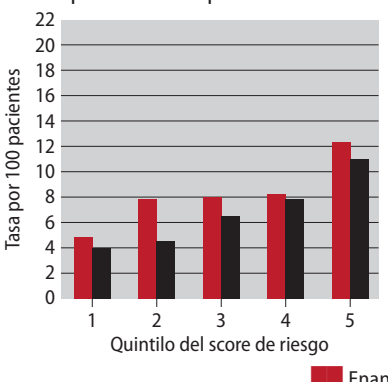

D. Muerte por todas las causas

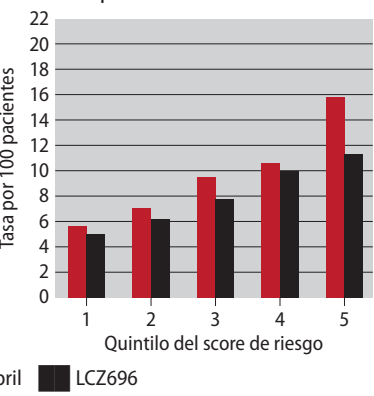

Figura 6. Después de clasificar a los pacientes del estudio PARADIGM-HF en quintiles en base la puntuación de riesgo del score MAGGIC, se determinó la tasa por cada 100 pacientes/año de seguimiento para: (A) el punto final primario compuesto, (B) muerte cardiovascular (CV), (C) hospitalizaciones por insuficiencia cardíaca (IC) y (D) mortalidad por todas las causas. La incidencia de todos los puntos finales aumentó progresivamente a mayor puntaje. El efecto de LCZ696 en comparación con enalapril fue consistentemente superior en reducir dicho riesgo. CV: cardiovascular. IC: insuficiencia cardiaca. Modificado de Simpson J, Jhund PS, Silva Cardoso J, Martinez F, Mosterd A, Ramires F, et al. Comparing LCZ696 With Enalapril According to Baseline Risk Using the MAGGIC and EMPHASIS-HF Risk Scores: An Analysis of Mortality and Morbidity in PARADIGM-HF. J Am Coll Cardiol 2015;66:2065.

Otro de los cuestionamientos que encontramos respecto del PARADIGM-HF es por qué se eligió compararlo con el enalapril, y no, por ejemplo, con el valsartán. Podemos decir que el estudio se propuso compararlo contra un fármaco de indicación clase I con nivel de evidencia A en IC. El valsartán está indicado en las guías como reemplazo del IECA en caso de no ser tolerado. También se discutió si la eficacia a favor del sacubitril/valsartán y en contra del enalapril, fue gracias al valsartán. Para ello, hemos revisado los principales estudios realizados con ARA II. Tanto el ELITE I como el ELITE I| compararon losartán con captopril, encontrándose que en ninguno de los dos casos el ARA II demostró superioridad respecto al IECA, ni en la inciden- 
cia de efectos adversos (ELITE I), ni en disminuir la mortalidad (ELITE II). Sin embargo, en el segundo, por ser un estudio no diseñado para probar no inferioridad, no se pudo afirmar que el losartán no fuera inferior al captopril. En otros ensayos, se decidió comparar si añadir un ARA II a pacientes ya tratados con IECA, disminuiría la mortalidad. Eso aconteció en el Val-HeFT, realizado con valsartán, y en el CHARMAdded, con candesartán, comparando con placebo. En ninguno de los dos se observó una disminución de la mortalidad a favor del agregado del ARA II. Incluso, en el Val-HeFT, se mostró aumento de la mortalidad. En el CHARM-Alternative, que comparó candesartán contra placebo, en los pacientes intolerantes al IECA, se advirtió una reducción de la mortalidad atribuida a dicho fármaco. Aun así, al día de hoy los ARA II no logran formar parte del grupo de los fármacos que disminuyen la mortalidad en IC con FEy disminuida (IECA, betabloqueantes y antagonistas de la aldosterona), y están indicados para los pacientes no toleren los IECA. Por ende, no podemos afirmar en base a los datos de la literatura actual que el beneficio demostrado en el PARADIGM-HF sea meramente gracias a la acción del valsartán.

Un punto que genera controversia en cuanto al fármaco, es por qué se necesita combinar al sacubitril con una segunda droga, y por qué se eligió un ARA II. Lo primero se explica por el hecho de que no alcanza solamente con inhibir la degradación de la neprilisina, sino que se necesita además bloquear el SRAA. Ya hemos enunciado el fracaso del candoxatril. El sacubitril otorgaría un efecto aditivo al aumentar los péptidos natriuréticos, pero no bastaría para atacar al desarreglo neurohormonal presente en la IC, por aumentar la AT II. Respecto al segundo punto, fue coherente haber elegido un ARA II para lograr ese cometido, puesto que ya se había analizado con el omapaprilat la combinación de un inhibidor de la neprilisina con un IECA, en el IMPRESS, en el OVERTURE y en el OCTAVE, lo que resultó en un incremento del angioedema y en la discontinuación del fármaco por la FDA. Esto tiene una explicación farmacológica, ya que al inhibir el SRAA, también se frena la degradación de bradiquininas, moléculas a las cuales se las responsabilizó por dicho aumento en la incidencia del angioedema. El ARA II, al actuar sobre un paso posterior de la cascada de SRAA, no aumenta las bradiquininas. Se podría atribuir a ello que el PARADIGM-HF no reportó mayor número de angioedema, y el éxito de su combinación ${ }^{41-43}$.

Respecto a la seguridad del fármaco, aún quedan algunos puntos por definir. El más conflictivo es el hecho de que aumentaría las posibilidades de desarrollar enfermedad de Alzheimer, dado que la proteína beta amiloidea es sustrato de la neprilisina. Debido a que el PARADIGM-HF fue suspendido prematuramente, no contamos con el tiempo suficiente para pesquisar dicho efecto en esa población, ni el estudio estaba diseñado para ello. Actualmente, se está llevando a cabo el PARAGON-HF, en el cual se está administrando el sacubitril/valsartán en pacientes con IC con fracción de eyección conservada, e incluye la evaluación neurocognitiva en el seguimiento de esta población $n^{51,53}$.

Como puntos de controversia respecto a los efectos adversos, es el mayor número de pacientes con hipotensión sintomática que generó el sacubitril/valsartán en el PARADIGM-HF, a pesar de que ello no produjo la suspensión del fármaco y que la diferencia promedio de tensión arterial fue sólo de 3,2 mmHg menor respecto al enalapril. Frente a este punto, nos volvemos a remitir al estudio TITRATION, el cual no tamizó a los pacientes, e incluyó tanto a los tolerantes a dosis altas como a bajas de IECA o ARA II, o ninguno, sin demostrar diferencias significativas entre ambos. También el mayor riesgo de angioedema, que a pesar de que no fue estadísticamente significativo, quedó latente, porque para realizar el estudio, se tamizó una población capaz de tolerar $20 \mathrm{mg} /$ día de enalapril, y sin historia previa de angioedema. A su vez, la población afro-americana, quienes presentarían mayor riesgo de angioedema, se reclutó en menor medida ${ }^{48}$.

Un punto a considerar en nuestro medio es el costo del sacubitril/ valsartán comparado con el del enalapril. A nivel mundial, sería muy importante contar con otro fármaco capaz de disminuir aún más la mortalidad de la insuficiencia cardíaca que el enalapril, no solo a nive personal, para poder otorgarle mejor calidad y expectativa de vida a cada paciente, sino también a nivel poblacional para reducir los gastos que esta patología genera, tan solo con el número de reinternaciones que produce anualmente, sin contar el costo de los tratamientos invasivos al llegar al estadio avanzado de la misma.

\section{CONCLUSIÓN}

En base a lo analizado, hemos visto que el advenimiento de los nuevos mecanismos de bloqueo neurohormonal con fármacos inhibidores de los receptores de la angiotensina y de la neprilisina, específicamente el sacubitril/valsartán, el primero en su clase, redujeron significativamente la mortalidad respecto a los inhibidores de la conversión de la angiotensina.

Como interrogantes, restan aún los análisis a futuro sobre la utilización de esta nueva droga en la población general, que no es la misma que la seleccionada para el ensayo clínico. Desconocemos aún cómo se comportará en otros tipos de poblaciones, quizás más comprometidas, como ya hemos visto a lo largo del trabajo, que no toleran la medicación clásica y a la dosis probada para reducir la mortalidad en la insuficiencia cardíaca, por lo que creemos que sería importante evaluar la efectividad del fármaco en el mundo real.

\section{BIBLIOGRAFÍA}

1. Mann DL. Tratamiento de los pacientes con insuficiencia cardiaca y fracción de eyección reducida. En Bonow R, Mann D, Zipes D, Libby P. Braunwald. Tratado de Cardiología: texto de medicina cardiovascular. (2015, Décima edición, 512-540). España: Editorial Elsevier.

2. Ponikowski P, Voors AA, Anker SD, Bueno H, Cleland JGF, Coats AJS, et al. ESC Guidelines for the diagnosis and treatment of acute and chronic heart failure. Rev Esp Cardiol 2016;69(12):1167.e1-e85.
3. Sociedad Argentina de Cardiología. Consenso de Insuficiencia Cardíaca Crónica. Rev Arg Cardiol. 2016;84(3):1-50.

4. Gradman AH. Evolving understanding of the rennin-angiotensin-aldosterone system pathophysiology and targets for therapeutic intervention. Am Heart J. 2009;157(6):1-6.

5. Hirvonen T, Pyorala K, Korhonen U, Takunen J, Gundersen T, Aslaksen B, et al. The CONSENSUS Trial Study Group. Effects of enalapril on mortality in severe congestive heart failure. N Engl J Med 1987;316(23):1429-1435. 
6. Nicklas JM, Timmis G, Breneman G, Jafri S, Duvernoy WFC, Davis SW, et al The SOLVD Investigators. Effect of enalapril on survival in patients with reduced left ventricular ejection fraction and congestive heart failure. N Engl J Med 1991:325(2):293-302

7. Nicklas JM, Pitt BP, Timmis G, Breneman G, Jafri SM, Duvernoy WFC, et al. The SOLVD Investigators. Effect of enalapril on mortality and the development of heart failure in asymptomatic patients with reduced left ventricular ejection fraction. N Engl I Med 1992;327(24):685-691.

8. Packer M, Bristow M, Cohn J, Colucci W, Fowler M, Gilbert E, et al. The effect of carvedilol on morbidity and mortality in patients with chronic heart failure. U.S. Carvedilol Heart Failure Study Group. N Engl J Med 1996;334(21):1349-1355.

9. Dargie H, Colucci W, Ford W, Lopez Sendon JL, Remme W, Sharpe N, et al. The CAPRICORN Investigators. Effect of carvedilol on outcome after myocardial infarction in patients with left-ventricular dysfunction: the CAPRICORN randomised trial. Lancet 2001;357(9266):1385-1390.

10. Packer M, Fowler MB, Roecker EB, Coats AJ, Katus HA, Krum H, et al. Effect of carvedilol on the morbidity of patients with severe chronic heart failure: results of the carvedilol prospective randomized cumulative survival (COPERNICUS) study. Circulation 2002:106(17):2194-2199.

11. Brunhuber KW, Hofmann R, Kühn P, Nesser HJ, Slany J, Weihs W, et al. The CIBIS II Investigators and Committees. A randomized trial of beta-blockade in heart failure. The cardiac insufficiency Bisoprolol Study II (CIBIS-II): a randomized trial. Lancet 1999;353(9146):9-13

12. Hjalmarson A, Goldstein S, Fagerberg B, Wedel H, Waagstein F, Kjekshus J, et al. MERIT-HF Study Group. Effect of metoprolol CRXL in chronic heart failure: Metoprolol CR/XL Randomised Intervention Trial in Congestive Heart Failure(MERIT-HF). Lancet 1999;353(9169):2001-2007.

13. Pitt B, Zannad F, Remme WJ, Cody R, Castaigne A, Perez A, et al. The effect of spironolactone on morbidity and mortality in patients with severe heart failure. Randomized Aldactone Evaluation Study Investigators. N Engl J Med 1999;341(10):709-717.

14. Pitt B, RemmeW, Zannad F, Neaton J, Martinez F, Roniker B, et al. Eplerrenone, a selective aldosterone blocker, in patients with left ventricular dysfunction after myocardial infarction. NEngl J Med 2003;348(14):1309-1321.

15. Zannad F, McMurray JJ, Krum H, van Veldhuisen DJ, Swedberg K, Shi H, et al. Eplerrenone in patients with systolic heart failure and mild symptoms. NEngl J Med. 2011;364(1): 11-21.

16. Pitt B, Segal R, Martinez FA, Meurers G, Cowley AJ, Thomas I, et al. Randomised trial of losartan versus captopril in patients over 65 with heart failure (Evaluation of Losartan in the Elderly Study, ELITE). Lancet 1997;349(9054):747-752.

17. Pitt B, Poole-Wilson PA, Segal R, Martinez FA, Dickstein K, Camm A, et al. Effect of Losartan compared with captopril on mortality in patients with symptomatic heart failure: randomized trial - the Losartan Heart Failure Survival Study ELITE II. Lancet 2000; 355(9215):1582-1587.

18. Cohn JN, Tognoni G; Valsartan Heart Failure Trial Investigators. A Randomized Trial of the Angiotensin-Receptor Blocker Valsartan in Chronic Heart Failure. N Engl J Med 2001;345(23):1667-1675.

19. Granger CB, McMurray JJ, YusufS, Held P, Michelson EL, Olofsson B, et al. Effects of candesartan in patients with chronic heart failure and reducer left-ventricular systolic function intolerant to angiotensin-converting-enzyme inhibitors: the CHARM-Alternative trial. Lancet 2003:362(9386):772-776.

20. Hasenfuss G, Mann DG. Fisiopatología de la insuficiencia cardíaca. En Bonow R, Mann D, Zipes D, Libby P. Braunwald. Tratado de Cardiología: texto de medicina cardiovascular. (2015, Décima edición, 454-473). España: Editorial Elsevier.

21. Maron BA, Rocco TP. Farmacoterapia de la insuficiencia cardiaca congestiva. En Brunton L, Chabner B, Knollman B. Goodman \& Gilman. Las bases farmacológicas de laterapéutica. (2012, Doceava Edición, 511-540). México: Editorial Mc Graw Hill.

22. Pitt B. "Escape" of aldosterone production in patients with left ventricular dysfunction treated with an angiotensin converting enzyme inhibitor: implications for therapy. Cardiovasc Drugs Ther. 1995; 9(1):145-149.

23. Maalouf $R$, Bailey $S$. A review on B-type natriuretic peptide monitoring: assays and biosensors. Heart failure reviews 2016;21(5):567-578.

24. Bold AJ, Borenstein HB, Veress AT, Sonnenberg H. A rapid and potent natriuretic response to intravenous injection of atrial myocardial extract in rats. Life sci. 1981; 28(1): 89-94.

25. Kone BC. Molecular biology of natriuretic peptides and nitric oxide synthases. CardiovasC Res 2001;51(3):429-441.

26. Sudoh T, Kangawa K, Minamino N, Matsuo H. A new natriuretic peptide in porcine brain. Nature 1988,332(6159):78-81.

27. Mukoyama M, Nakao K, Hosoda K, Suga S, Saito Y, Ogawa Y, et al. Brain natriuretic peptide as a novel cardiac hormone in humans. Evidence for an exquisite dual natriuretic peptide system, atrial natriuretic peptide and brain natriuretic peptide. J Clin Invest 1991:87(4):1402-1412.

28. Ichiki T, Huntley BK, Heublein DM, Sandberg SM, McKie PM, Martin FL, et al. Corin is present in the normal human heart, kidney, and blood, with pro-B-type natriuretic peptide processing in the circulation. Clin Chem 2011;57(1):40-47.

29. Langenickel T, Dole W. Angiotensin receptor neprylisin inhibition with LCZ696: a novel approach for the treatment of heart failure. Drug Discovery Today Therapeutic Strategies 2014;9(4):131-139.
30. Marcus LS, Hart D, Packer M, Yushak M, Medina N, Danziger RS, et al. Hemodynamic and renal excretory effects of human brain natriuretic peptide infusion in patients with congestive heart failure. A double-blind, placebo-controlled, randomized crossover trial. Circulation 1996:94(12):3184-3189.

31. Hayashi D, Kudoh S, Shiojima I, Zou Y, Harada K, Shimoyama M, et al. Atrial natriuretic peptide inhibits cardiomyocite hypertrophy through mitogen-activated protein kinase phosphatase-1. Biochem Biophys Res Commun 2004;322(1):310-319.

32. Maisel AS, Krishnaswamy P, Nowak RM, McCord J, Hollander JE, Duc P, et al. Rapid measurement of $B$-Type natriuretic peptide in the emergency diagnosis of heart failure. $N$ Engl J Med 2002;347(3):161-167.

33. Januzzi JL Jr, Camargo CA, Anwaruddin S, Baggish AL, Chen AA, Krauser DG, et al. The $\mathrm{N}$-terminal Pro-BNP investigation of dyspnea in the emergency department (PRIDE) study. Am J Cardiol 2005;95(8):948-954.

34. Silver MA, Maisel A, Yancy CW, McCullough PA, Burnett JC Jr, Francis GS, et al. BNP Consensus Panel 2004: A clinical approach for the diagnostic, prognostic, screening, treatment monitoring, and therapeutic roles of natriuretic peptides in cardiovascular diseas es. Congestive Heart Fail 2004; 10(5): 1-30.

35. Januzzi JL, Mann DL. Valoración clínica de la insuficiencia cardíaca En Bonow R, Mann D, Zipes D, Libby P. Braunwald. Tratado de Cardiología: texto de medicina cardiovascular. (2015, Décima edición, 473-484). España: Editorial Elsevier.

36. Wang TJ, Larson MG, Levy D, Benjamin EJ, Leip EP, Wilson PW, et al. Impact of obesity on plasma natriuretic peptide levels. Circulation. 2004, 109(05): 594-600.

37. Miller WL, Phelps MA, Wood CM, Schellenberger U, Van Le A, Perichon R, et al. Comparison of mass spectrometry and clinical assay measurements of circulating fragments of B-type natriuretic peptide in patients with chronic heart failure. Circ Heart Fail 2011;4(3):355-60.

38. Thierer, J. Fisiopatología. En Thierer J. Insuficiencia cardíaca: evidencia, experiencia y opinión (2014, primera edición, 287-295). Buenos Aires: Editorial Intermédica.

39. Elsner D, Müntze A, Kromer EP, Riegger GA. Effectiveness of endopeptidase inhibition (candoxatril) in congestive heart failure. Am J Cardiol 1992;70(4):494-498.

40. Richards AM, Wittert GA, Crozier IG, Espiner EA, Yandle TG, Ikram H , et al. Chronic inhibition of endopeptidase 24.11 in essential hypertension: evidence for enhanced atrial na triuretic peptide and angiotensin II. J Hypertens 1993;11 (4):407-416.

41. Rouleau JL, Pfeffer MA, Stewart DJ, Isaac D, Sestier F, Kerut EK, et al. Comparison of vasopeptidase inhibitor, omapatrilat, and lisinopril on exercise tolerance and morbidity in patients with heart failure: IMPRESS randomized trial. Lancet 2000;356(9230):615-620.

42. Packer M, Califf RM, Konstam MA, Krum H, McMurray JJ, Rouleau JL, et al. Comparison of omapatrilat and enalapril in patients with chronic heart failure: the Omapatrilat Versus Enalapril Randomized Trial of Utility in Reducing Events (OVERTURE). Circulation 2002;106(8):920-926

43. Kostis JB, Packer M, Black HR, Schmieder R, Henry D, Levy E. Omapatrilat and enalapril in patients with hypertension: the Omapatrilat Cardiovascular Treatment vs. Enalapril (OCTAVE) trial. Am J Hypertens 2004;17(2):103-111.

44. Tyler JM, Teerlink JR. The safety of sacubitril-valsartan for the treatment of chronic heart failure. Expert Opin Drug Saf. 2017;16(2):257-263.

45. Gu J, Noe A, Chandra P, Al-Fayoumi S, Liqueros-Saylan M, Sarangapani R, et al. Pharmacokinetics and pharmacodynamics of LCZ696, a novel dual-acting angiotensin receptor-neprilysin inhibitor (ARNi). J Clin Pharmacol. 2010; 50(4):401-414.

46. MCMurray JJ, Packer M, Desai AS, Gong J, Lefkowitz MP, Rizkala AR, et al. Angiotensin-neprilysin inhibition versus enalapril in heart failure. N Engl J Med. 2014; 371(11) 993-1004.

47. Packer M, McMurray JJ, Desai AS, Gong J, Lefkowitz MP, Rizkala AR, et al. Angiotensin receptor neprilysin inhibition compared with enalapril on the risk of clinical progression in surviving patients with heart failure. Circulation 2015;131(1):54-61.

48. Senni M, McMurray JJ, Wachter R, McIntyre HF, Reyes A, Majercak I, et al. Initiating sacubitril/valsartan (LCZ696) in heart failure: results of TITRATION, a double-blind, random ized comparison of two uptitration regimens. Eur J Heart Fail 2016;18(9):1193-1202.

49. Simpson J, Jhund PS, Silva Cardoso J, Martinez F, Mosterd A, Ramires F, et al. Comparing LCZ696 With Enalapril According to Baseline Risk Using the MAGGIC and EMPHASIS-HF Risk Scores: An Analysis of Mortality and Morbidity in PARADIGM-HF. J Am Coll Cardiol 2015;66(19):2059-2071.

50. Fala L. Entresto (SacubitrilNalsartan): First-in-Class Angiotensin Receptor Neprilysin Inhibitor FDA Approved for Patients with Heart Failure. Am Health Drug Benefits 2015;8(6),330-334.

51. Vodovar N, Paquet C, Mebazaa A, Launay JM, Hugon J, Cohen-Solal A. Neprilysin, Cardiovascular, and Alzheimer's diseases: the therapeutic split? Eur Heart J 2015;36(15):902-905.

52. Bayes-Genis A, Lupón J. Neprilisina: indicaciones, expectativas y retos. Rev Esp Cardiol 2016;69(7):647-649.

53. Solomon SD, Rizkala AR, Gong J, Wang W, Anand IS, Ge J, Pfeffer MA et al. Angiotensin receptor neprilysin inhibition in heart failure with preserved ejection fraction: rationale and design of the PARAGON-HF trial. JACC: Heart Failure 2017;5(7):471-482.

54. Yancy C, Jessup M, Bozkurt B, Butler J, Casey D Jr., M.Colvin M, et al. 2016 ACC/AHAVHFSA Focused Update on New Pharmacological Therapy for Heart Failure: An Update of the 2013 ACCF/AHA Guideline for the Management of Heart Failure: A Report of the American College of Cardiology/American Heart Association Task Force on Clinical Practice Guidelines and the Heart Failure Society of America. J Am Coll Cardiol 2016;68(13):1476-1488. 